\title{
RELATO INTEGRADO E O FORMATO DA INFORMAÇÃO FINANCEIRA PARA EVIDENCIAR A CRIAÇÃO DE VALOR DAS EMPRESAS DO PROGRAMA PILOTO ${ }^{1}$
}

\section{INTEGRATED REPORT AND THE FINANCIAL INFORMATION FORMAT TO EVI- DENCE THE VALUE CREATION OF PILOT PROGRAM ENTERPRISES}

\author{
Nadson Jaime Ferreira Alves ${ }^{2}$ \\ Doutorando em Administração pela Universidade de São Caetano do Sul \\ Professor da Universidade Federal do Pará \\ nadson@ufpa.br \\ José Roberto Kassai \\ Doutor em Controladoria e Contabilidade pela Universidade de São Paulo \\ Professor da Universidade de São Paulo \\ jrkassai@usp.br

\section{Edimilson Costa Lucas} \\ Doutor em Administração pela Fundação Getúlio Vargas \\ Professor da Universidade Municipal de São Caetano do Sul \\ edimilson.costa@uscs.edu.br

\section{Humberto Medrado Gomes Ferreira} \\ Titulação e onde obteve a titulação \\ Doutorando em Administração pela Universidade Municipal de São Caetano do Sul \\ hmedrado@gmail.com
}

\section{RESUMO}

Objetivo: descrever o conteúdo e a forma de evidenciação da criação de valor por meio das informações financeiras no Relato Integrado, a partir da publicação do Framework, em dezembro/2013.

Fundamento: diante do paradigma da responsabilidade social das organizações, o propósito da comunicação corporativa é evidenciar as diversas informações que afetam a criação de valor e ampliar o acesso por diferentes usuários. Esse também é o propósito do Relato Integrado [RI] ao conectar informações de seis capitais (financeiro, humano, intelectual, natural, manufaturado e de relacionamento) que levam ao pensamento integrado necessário para expressar como a empresa cria valor, no curto, médio e longo prazo, em linguagem concisa, conexa, completa e comparável, conforme framework do RI.

Método: pesquisa documental com apoio do Software Nvivo 11, nos Relatos Integrados das empresas que participam do Programa Piloto [PP] no Brasil, nos anos de 2014 e 2015.

\footnotetext{
${ }_{1}$ Artigo recebido em: 05/05/2017. Revisado por pares em: 04/07/2017. Reformulado em: 16/08/2017. Recomendado para publicação em: 16/08/2017 por Luiz Felipe de Araújo Pontes Girão (Editor Geral). Publicado em: 31/08/2017. Organização responsável pelo periódico: UFPB.

2 Endereço: Rua Augusto Corrêa, 1 - Guamá, Belém - PA, 66075-110.

DOI: http://dx.doi.org/10.18405/recfin20170306
} 
Resultados: foi constatado uso limitado de alguns termos que fundamentam o RI e a informação financeira oriunda das Demonstrações Contábeis. Mas, também, foi identificado o uso de linguagem visual em sintonia com os princípios da concisão, completude, comparabilidade e conectividade nas informações dos RI.

Contribuições: ao meio acadêmico contribui para constatar a abordagem interdisciplinar do Relato Integrado ao conectar propósitos da Administração, da Contabilidade e da Comunicação. Às empresas, contribuiu na tomada de decisão ao mostrar a interface entre forma e conteúdo na evidenciação da criação de valor, além de desdobrar o Framework do RI.

Palavras-chave: Relato integrado. Criação de valor. Informação financeira. Contabilidade. Linguagem visual.

\section{ABSTRACT}

Objective: to describe the content and form of evidence of value creation through financial reporting in the Integrated Report, as of the publication of the Framework, in December / 2013.

Fundamentals: in front of the corporate social responsibility paradigm, the purpose of corporate communication is to highlight the diverse information that affects the creation of value and to increase access by different users. This is also the purpose of the Integrated Report [IR] in connecting information from six capitals (financial, human, intellectual, natural, manufactured, and relationship) leading to the integrated thinking necessary to express how the company creates value in the short, medium and long term, in clear and concise language, related and comparable language, according to the IR framework.

Method: documentary research supported by Software Nvivo 11, in the Integrated Reports of companies participating in the Pilot Program [PP] in Brazil, in 2014 and 2015.

Results: there was a limited use of some terms underlying the IR and the financial information derived from the Financial Statements. However, the use of visual language was also identified in line with the principles of conciseness, completeness, comparability and connectivity in IR information. Contributions: to the academic environment contributes to verify the interdisciplinary approach of the Integrated Report in connecting Management, Accounting and Communication purposes. To companies, it contributed to decision making by showing the interface between form and content in the evidence of value creation, as well as deploying the IR Framework.

Keywords: Integrated report. Value creation. Financial information. Accounting. Visual language.

\section{INTRODUÇÃO}

Com a tecnologia de informação e comunicação, o mundo vivencia, como nunca, a era da conexão. Conexão de culturas, de pessoas, de ideias, de temas, de atividades. Isso sinaliza ao universo empresarial que a sustentabilidade das organizações, também, depende da sinergia entre diferentes aspectos, dentre eles o econômico, o social e o ambiental; o chamado Triple botton line (Jensen \& Berg, 2012), sob mediação da comunicação corporativa.

Para o Institute of Chartered Accountant of England and Wales [ICAEW] (2009), os modelos de relatórios corporativos evoluem, se adaptam às mudanças de fatores ambientais. Mas, certos atritos interferem nesse desenvolvimento e levam à inadequada compreensão e resolução de problemas dos relatórios corporativos, tais como: regulação imprudente, necessidades de reguladores que suplantam às necessidades de usuários, litígios excessivos entre os interessados.

O International Integraste Reporting Council [IIRC] (2011), entidade articuladora do Relato Integrado no mundo, ao retratar a trajetória de evolução dos relatórios corporativos destaca, na década de 60, o Relatório Financeiro era exclusivo. A partir dos anos 80, surgiram os Relatórios de Governança e de Sustentabilidade. Nos anos 2.000, ganhou evidência o Relatório de Administração. Mas 
até então, eram relatórios separados, com informações estanques, condição determinante para o surgimento do Relato Integrado, na atualidade.

Para Havlová (2015), a questão da integração de relatórios surgiu como consequência do crescente número de relatórios emitidos pelas empresas, para suprir a demanda de informações para a tomada de decisão, especialmente, de investidores. Mas nem sempre tais informações chegam há tempo, de forma acessível e articulada. Esse é o propósito do Relato Integrado [RI], inovação na comunicação que não substitui os demais relatórios corporativos, mas conecta-os na busca do alinhamento, da complementariedade.

Conforme o IIRC (2013), trata-se de comunicação concisa sobre a forma como a estratégia, a governança, o desempenho e as perspectivas da organização levam à criação de valor no contexto da organização e sob a ótica dos seis capitais (financeiro, manufaturado, intelectual, humano, social/de relacionamento e natural).

A criação de valor resulta da maneira como a organização usa os diversos capitais e apura seus afeitos no decorrer do tempo, ao interagir com o ambiente externo. Tais capitais são repositórios de valor, aumentam, diminuem ou se transformam por meio de atividades e produtos da organização (IIRC, 2013).

Além de dirimir informações inconsistentes e até contraditórias entre diferentes relatórios corporativos, o RI propõe conteúdos conexos em linguagem concisa para evidenciar a criação de valor (Eccles \& Krzus, 2011). Logo, a informação financeira tem que estar propensa à integração.

Até porque, o texto deve funcionar como um todo orgânico, a forma não pode se sobrepor ao conteúdo; e o conteúdo não pode se sobrepor à forma, para evitar o ruído na comunicação com a presença de elementos que impedem a presença do leitor, que o afastam do texto (Perrotta, 2004).

Assim, este artigo tem como questão de pesquisa: como as informações financeiras evidenciam a criação de valor, no Relato Integrado das empresas do Programa Piloto no Brasil, nos anos de 2014 e 2015? O objetivo é descrever o conteúdo e a forma de evidenciação da criação de valor por meio das informações financeiras no RI, a partir da publicação do Framework, em dezembro/2013.

Tal estudo se justifica pela necessidade de analisar como a informação financeira se integra aos demais conteúdos, em linguagem acessível, para evidenciar a criação de valor e, assim, dar feedback às equipes de elaboradores e organismos que acompanham a implantação do RI. O diferencial está na análise que vai além do conteúdo, ao envolver, também, a forma de evidenciação das informações.

Para tanto, a pesquisa se baseia em dezoito relatos de nove empresas, das doze que participam do programa piloto no Brasil: AES Brasil, BNDES, BRF, CCR, CPFL Energia, Fibria, Itaú/Unibanco, Natura e Votorantim Cimentos.

Devido a curta trajetória do RI e o tamanho da amostra, optou-se pela flexibilidade da pesquisa qualitativa (documental) desenvolvida em quatro níveis, com auxílio do Software Nvivo 11 for Windows: (i) mapeamento da estrutura dos relatos; (ii) mapeamento da frequência de termos que fundamentam o Relato Integrado; (iii) mapeamento da frequência de termos da informação financeira, oriundos das Demonstrações Contábeis, bem como a frequência de termos da informação não financeira; e (iv) análise da predisposição de integração das informações financeiras, por meio da linguagem visual, com base na concisão, completude, conectividade e comparabilidade.

Além da introdução (Unidade 1), este artigo está estruturado em quatro outras partes. Unidade 2 - Referencial teórico sobre a evolução dos relatórios corporativos, criação de valor e forma de evidenciação. Unidade 3 - Metodologia. Unidade 4 - Descrição e análise dos resultados. Unidade 5 Conclusões da pesquisa. 


\section{REFERENCIAL TEÓRICO}

\subsection{Relato Integrado, Relatório Financeiro e Relatório não Financeiro}

O RI resulta da conexão entre Relatório Financeiro e Relatórios não Financeiros em prol do pensamento integrado, a visão holística do processo de criação de valor. O objetivo é explicar a provedores de capital financeiro como a organização gera valor ao longo do tempo, por meio de informações relevantes (IIRC, 2013).

O Relatório Financeiro é composto pelas Demonstrações Contábeis, expresso por meio do relatório anual obrigatório, com a estrutura conceitual definida por entidades reguladoras em relação a mensuração e divulgação dos elementos patrimoniais. Ao passo que, os Relatórios não Financeiros retratam informações sobre estratégia, sustentabilidade, governança, estruturas, sistemas e métodos de atuação das organizações e, quase sempre, são de caráter voluntário (Da Cunha, Morais \& Rodrigues, 2016).

Para o Conselho Federal de Contabilidade [CFC], as Demonstrações Contábeis (Quadro 1) devem ser apresentadas aos usuários externos em geral, face a finalidades distintas e necessidades diversas.

Quadro 1: Demonstrações Contábeis - Finalidades

Demonstrações Contábeis

Balanço Patrimonial [BP]

\section{Finalidades}

Retratar a composição do patrimônio, em determinada data, classificados em investimentos (ativos) e financiamentos (passivos e patrimônio líquido), a fim de mostrar as informações da maneira mais útil aos usuários para a tomada de decisões econômicas.

\begin{tabular}{l|l}
\hline $\begin{array}{l}\text { Demonstração do Resultado do } \\
\text { Exercício [DRE] }\end{array}$ & $\begin{array}{l}\text { Apurar o resultado econômico da entidade no período, por meio de } \\
\text { elementos que mensuram o desempenho, receitas e despesas. }\end{array}$ \\
\hline $\begin{array}{l}\text { Demonstração das Mutações do } \\
\text { Patrimônio Líquido [DMPL] }\end{array}$ & $\begin{array}{l}\text { Detalhar alterações qualitativos e quantitativos nos elementos do patrimônio } \\
\text { líquido, a partir de eventos evidenciados no BP e/ou na DRE. }\end{array}$ \\
\hline $\begin{array}{l}\text { Demonstração dos Fluxos de } \\
\text { Caixa [DFC] }\end{array}$ & $\begin{array}{l}\text { Detalhar o desempenho financeiro da entidade no período, ao reportar o con- } \\
\text { trole do caixa, segmentado em três atividades: operacional, investimento e } \\
\text { financiamento. }\end{array}$ \\
\hline $\begin{array}{l}\text { Demonstração do Valor Adicio- } \\
\text { nado [DVA] }\end{array}$ & $\begin{array}{l}\text { Apurar o valor agregado pela empresa, no período, e a distribuição aos agen- } \\
\text { tes: acionistas, terceiros, governo e colaboradores. }\end{array}$ \\
\hline
\end{tabular}

Fonte: CFC (2008), CFC (2011) e CFC (2016)

Por sua vez, cada Relatório não Financeiro tem orientações de entidades específicas como a Comissão de Valores Mobiliários [CVM], Global Reporting Inititative [GRI] e o Instituto Brasileiro de Governança Corporativa [IBGC], Quadro 2.

Quadro 2: Relatórios não Financeiros

\section{Relatórios} Finalidades

\begin{tabular}{l|l}
$\begin{array}{l}\text { Relatório de Adminis- } \\
\text { tração }\end{array}$ & $\begin{array}{l}\text { Complementar as demonstrações contábeis com informações orientadas ao futuro ou } \\
\text { análises do passado que indiquem tendências futuras com efeito na tomada de deci- } \\
\text { são. Usa linguagem acessível, por ser instrumento de comunicação entre a entidade, } \\
\text { os acionistas e a comunidade (CVM, 2005). }\end{array}$ \\
\hline $\begin{array}{l}\text { Relatório de Sustentabi- } \\
\text { lidade }\end{array}$ & $\begin{array}{l}\text { Relatar a sustentabilidade da empresa baseada em três categorias macros: ambiental, } \\
\text { social e econômico, que norteiam a coleta de dados e informações quantitativas e } \\
\text { qualitativas, úteis para materializar a prestação de contas da organização de forma } \\
\text { mais acessível (GRI, 2013). }\end{array}$ \\
\hline $\begin{array}{l}\text { Governança Corpora- } \\
\text { tiva }\end{array}$ & $\begin{array}{l}\text { Assegurar que os relatórios contribuam para melhor avaliação da qualidade gerencial } \\
\text { da organização e dos riscos a que está disposta a se submeter. Comunicação ade- } \\
\text { quada, por meio de mecanismos formais, a fim de evitar assimetria de informações } \\
\text { com as partes interessadas. (IBGC, 2015) }\end{array}$ \\
\hline
\end{tabular}

Fonte: CVM (2005), GRI (2013), IBGC (2015) 
Em ambientes competitivos, os Relatórios não Financeiros ajudam as organizações a perceber se as vantagens estratégicas serão sustentáveis, se respondem a pressões internas e externas e, assim, gerir e evidenciar a responsabilidade social e ambiental da organização (Klovienė \& Speziale, 2014).

Contudo, críticas apontam limitações nos relatórios corporativos. No caso do Relatório Financeiro: (i) foco no passado, mais histórico do que prospectivo; (ii) foco em informação de natureza monetária, enquanto os usuários também precisam de informações qualitativas; (iii) diferença entre os valores evidenciados no balanço e os valores de mercado das empresas, pela ausência de elementos intangíveis relevantes nas demonstrações contábeis (DaCunha et al., 2016).

A evolução dos ativos intangíveis explica, em parte, a insuficiência da informação financeira na tomada de decisão. Segundo a Ernst \& Young (2014), uma das maiores empresas de auditoria, os regulamentos contábeis vigentes limitam a capacidade de reconhecer, no Balanço Patrimonial, os ativos intangíveis gerados internamente.

A Figura 1 retrata a influência dos ativos intangíveis no valor de mercado das empresas que compõem o índice Standard \& Poor's 500, com as quinhentas maiores ações cotados nas Bolsas de Nova Iorque [NYSE] e National Association of Securities Dealers Automated Quotations [NASDAQ].

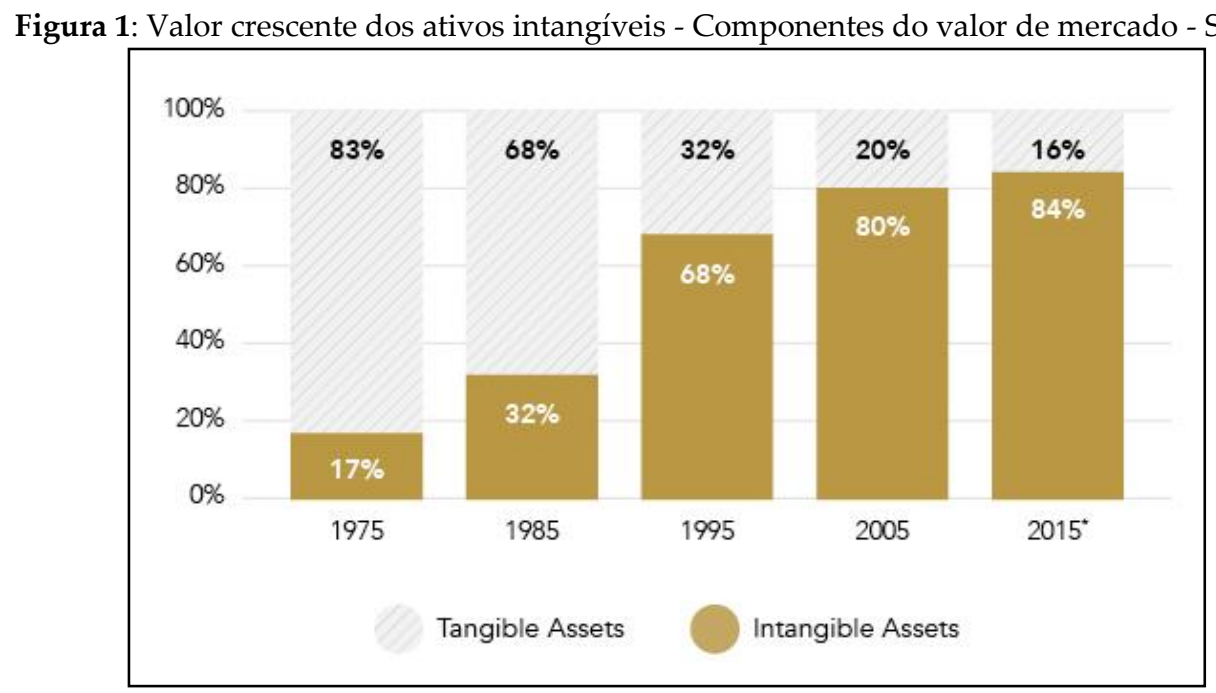

Fonte: Ocean Tomo (2015)

Pela Figura 1, percebe-se a prevalência dos ativos intangíveis na atualidade, muitos gerados internamente e não considerados na mensuração contábil, como o capital de relacionamento, que afeta a sustentabilidade da organização, expondo limitações da informação financeira ao evidenciar a criação de valor.

Mazzioni, Di Domenico e Bedin (2014), em pesquisa com empresas listadas na BM\&FBOVESPA, sobre evidenciação compulsória de ativos intangíveis previsto no CPC 04, constataram, o índice de conformidade, por empresa, variou entre $95 \%$ e $0 \%$.

E apesar do grande avanço com a harmonização das Normas Internacionais de Contabilidade a partir de 2005, outra crítica recorrente aos relatórios financeiros publicados, diz respeito às limitações de tais informações para fins gerenciais. Entretanto, a informação contábil não é única, há diferenças entre a Contabilidade Financeira e a Contabilidade Gerencial, conforme demonstra a Figura 2. 
Figura 2: Comparação entre Contabilidade Financeira e Contabilidade Empresarial CONTABILIDADE

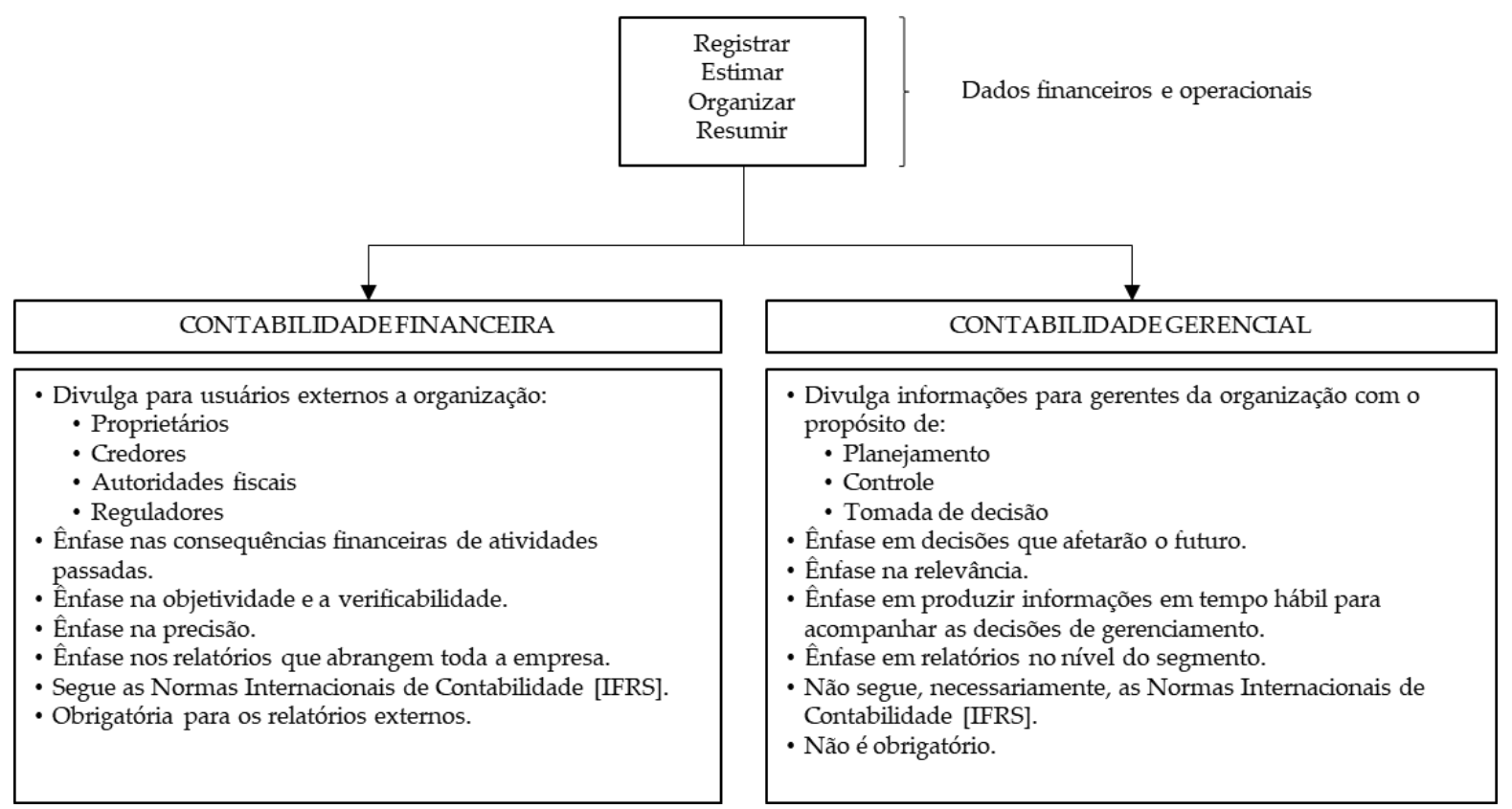

Fonte: Garrison, Norren e Brever (2013, p. 2)

Pela Figura 2, vê-se que muitas das críticas à informação contábil, na verdade são críticas a informação contábil para fins externos (Contabilidade Financeira). E, com o Relato Integrado, a linha divisória dessa dicotomia na Contabilidade fica cada vez mais tênue devido a demanda dos investidores também por informações gerenciais e não financeiras para avaliar, com mais propriedade, a criação de valor pela organização.

Eccles e Spiesshofer (2015) também constataram limitações nos Relatórios não Financeiros, a divulgação inicial de informação sobre responsabilidade social, ambiental e econômica, em relatórios independentes, dificultou o entendimento dos usuários pela falta de conexão entre os diferentes impactos, e o problema não é recente.

Em 2004, surgiu o Princes Accounting for Sustainability Project [A4S], grupo capitaneado pelo Príncipe Charles da Inglaterra, com intuito de conectar relatórios corporativos (Da Cunha et al., 2016). Desse movimento, em dezembro de 2009, surgiu o IIRC, coalizão global de reguladores, investidores, empresas, definidores de padrões, profissionais do setor contábil e ONGs, para emitir padrões gerais do RI, dar suporte aos usuários e sistematizar as experiências (Programa Piloto) com empresas de vários segmentos e países, inclusive o Brasil. Dentre as entidades parceiras está o International Accounting Standards Board [IASB].

Para viabilizá-lo em distintos países e empresas, o RI é baseado em princípios gerais e não em normas específicas: "foco estratégico e orientação para o futuro, conectividade da informação, relações com partes interessadas, materialidade e concisão, confiabilidade e completude, coerência e comparabilidade" (IIRC, 2013, p. 17).

O Framework do RI prevê os seguintes conteúdos: "visão geral organizacional e ambiente externo, governança, modelo de negócios, riscos e oportunidades, estratégia e alocação de recursos, desempenho, perspectivas e base de preparação" (IIRC, 2013, p. 25).

Mas, conforme Da Cunha et al. (2016), há desafios para integrar a informação não financeira aos relatórios tradicionais, presos, essencialmente, às informações financeiras. A meta é reduzir a complexidade da informação divulgada para proporcionar, aos investidores e outros usuários, a informação necessária para conhecer as empresas, avaliar desempenhos e tomar decisões. Mudanças 
que demandam tempo para construir indicadores de desempenho (integrados e robustos), alinhados às novas demandas de informações.

Carvalho e Kassai (2014) alertam, o RI não é junção banal entre relatórios, mas processo de convergência entre sistemas de gestão organizacional e comunicação corporativa, no tempo de cada empresa para que os profissionais envolvidos se adaptem ao modelo de negócio que sintoniza sociedade, natureza e fluxos de caixa.

A Ernst \& Young (2014, p. 4) resume, "o relato integrado tem por objetivo rastrear de que forma os vários tipos de capital são utilizados, como se relacionam e as compensações realizadas pelas organizações".

Mas Pereira (2016), em pesquisa com uma amostra de seis outras empresas europeias, integrantes do Corporate Leadership Group on integrated reporting, no período de 2015, constatou, entre outros aspectos elementares, que os relatórios não foram identificados como Relato Integrado, apesar de seguirem outras orientações.

Portanto, conforme Carvalho e Kassai (2014), o RI envolve: (i) mudança de cultura nas organizações e partes interessadas; (ii) regulações internacionais e locais; e (iii) resultados a longo prazo. Pois, diante do desafio de um mundo melhor e menos desigual, será necessário reconhecer e atribuir valor às externalidades sociais e ambientais em toda a cadeia produtiva, para que os agentes econômicos internalizem tais custos. E a Contabilidade, por meio de sua metodologia (conhecer-identificar-mensurar-reportar), precisa avaliar o patrimônio de forma retrospectiva e prospectiva, em suporte a demandas de um modelo econômico mais sustentável. Assim, as empresas descobrirão novas formas de criação de valor ao acionista, em modelos de negócios que articulem diferentes capitais.

\subsection{Criação de Valor}

Conforme o IIRC (2013), a organização usa e afeta diversos capitais responsáveis por gerar valor no curto, médio e longo prazo. Tais capitais são repositórios de valor, aumentam, diminuem ou se transformam por meio de atividades e produtos da organização.

Da Silva (2011) destaca, tanto a Teoria dos Stakeholders quanto a visão baseada em recursos são abordagens com influência na criação de valor. A primeira entende que a criação de valor decorre da forma como os interesses dos diversos grupos são atendidos. Por outro lado, na segunda, as organizações podem ser observadas em termos de recursos (pontos fortes e fracos), e a criação de valor dá-se a partir da forma de gestão destes recursos.

Quando o IIRC (2013) anuncia, a capacidade de a organização gerar valor para si está relacionada ao valor que gera aos outros; aflora a abordagem baseada na Teoria dos Stakeholders. Mas o uso de relatórios financeiros e de indicadores para avaliar o desempenho, em certa medida, contempla a abordagem baseada em recursos. Logo, o RI trabalha com as duas abordagens, ao conectar capital financeiro e capital de relacionamento, dentre outros.

De certo, a criação de valor é o eixo principal do RI, rota do futuro nos relatos corporativos, pois as organizações dependem de recursos cada vez mais escassos e alguns pertencem à sociedade. Logo, o valor criado pela organização deve ser compartilhado entre proprietários, sociedade e outras partes interessadas (Ernst \& Young, 2014).

Nessa linha, o RI deve divulgar atividades, interações e demais externalidades relevantes à capacidade de a organização gerar valor, positivo ou negativo, para os provedores de capital avaliarem efeitos e alocarem recursos de forma consciente. Até porque, o valor é gerado ao longo de diversos períodos, com variados capitais, pois é improvável ser maximizado por um único tipo capital, em detrimento dos demais (IIRC, 2013).

Assim, parte essencial do RI descreve como a estratégia e o modelo de negócios articulam os capitais a serem convertidos em criação de valor, e como medi-los pelos indicadores de desempenho, 
ao retratar impactos nos ativos tangíveis e intangíveis da organização e avaliar o efeito no valor da organização para o acionista (Ernst \& Young, 2014).

Gonzaga et al. (2015) propõem o Earnings Before Interest, Taxes, Depreciation and Amortization [EBITDA] como indicador de desempenho para avaliar a missão institucional declarada das empresas. Por sua vez, Lopes et al. (2017) ressaltam que nas pesquisas que adotam como construto a criação de valor, normalmente se utilizam do Return On Assets [ROA] e do Return On Equity [ROE], como indicadores de desempenho, em vez de variáveis como Economic Value Added [EVA] e Market Value Added [MVA]. Mas são indicadores de desempenho financeiro. E, para o RI, precisam acrescentar aspectos não financeiros.

Desta feita, para a International Federation of Accountants [IFAC] (2015), essa abordagem de criação de valor requer planejamento integrado e tomada de decisões atentas às oportunidades e riscos significativos. E esse nível de integração depende da conexão de pessoas, funções, sistemas e informações financeiras e operacionais, internas e externas.

E mais, o indicador de informações integradas pode gerar efeitos simultâneos. Ao comparar investimentos em novos equipamentos versus consumo de energia, pode-se medir indiretamente a criação de valor pelo desempenho financeiro (efeito nos custos e na lucratividade), desempenho ambiental (efeito no nível de consumo de energia) e desempenho social (efeito na produtividade dos funcionários ou, ainda, na reputação perante clientes) (Ernst \& Young, 2014).

Portanto, ao integrar relatórios financeiros e não financeiros, a gestão eficaz do risco fica mais evidente para garantir a viabilidade das metas estratégicas de criação de valor. Entretanto, divulgações de empresas transparentes, precisam equilibrar os custos da informação aos benefícios para investidores (Roth, 2014, Eccles \& Spiesshofer, 2015). Por isso precisam explorar as potencialidades do conteúdo e da forma de evidenciação.

\subsection{Forma de evidenciação}

Silva (2006), ao analisar a obra de Michael Maffesoli, afirma, a comunicação remete à sociedade da informação, em que o indivíduo só é o que é na relação com outras pessoas. Para tanto, informar significa pôr em forma e comunicar é construir algo comum. Ambas, envolvem participação e intenção do discurso. Nunca são palavras e formatos neutros.

Nessa linha, evidenciar a criação de valor em sintonia com os princípios previstos no Framework (IIRC, 2013), remete a necessidade de refletir sobre a forma de divulgação, pois, devido a quantidade e variedade de conteúdo, é essencial selecionar o que deve ser evidenciado. E a Matriz de Materialidade (Ferreira-Quilici \& Caldana, 2015), ferramenta do Relatório de Sustentabilidade, ajuda a identificar os temas mais relevantes, ao ponderar o ponto de vista dos principais stakeholders e dos gestores da empresa.

E como, no RI, as informações podem ser sintetizadas em aspectos relevantes e formatos diferenciados, inclusive a informação financeira, o uso da linguagem visual cumpre importante função na acessibilidade da informação. Daí o uso de formas, cores, espaços, texturas, sons e movimentos que despertam a percepção do usuário e facilitam o entendimento da mensagem (Lencastre \& Chaves, 2007). As possibilidades de interpretação crescem povoadas por novos signos da revolução digital, que disseminou o uso de hipertexto, hipermídia e infográfico (Santaella, 2002).

Portanto, o Relato Integrado inova na forma de comunicar a criação de valor, tanto pela conexão de diferentes conteúdos, quanto pela forma expressão da informação. O que reforça a necessidade de investigar a predisposição da informação financeira nesse processo. 


\section{METODOLOGIA DE PESQUISA}

Como esta pesquisa descreve conteúdo e forma de evidenciação da criação de valor via informações financeiras nesses primeiros anos de RI, o parâmetro para análise é o potencial de integração das informações nos relatos pesquisados, em sintonia com quatro princípios do RI: conectividade, concisão, completude e comparabilidade.

Esse tema surgiu pelo fato da Contabilidade ser um sistema de informação, mas na formação de contador aborda-se pouco os fundamentos da comunicação. E agora, com o Relato Integrado, é oportuno refletir sobre a qualidade da informação financeira e sua predisposição para integração com outras informações.

Na primeira etapa deste estudo teórico-empírico, buscou-se conhecer as orientações específicas sobre divulgação de informações no RI. Na pesquisa bibliográfica, foi verificado que, apesar do crescente número de publicações sobre o assunto, nenhuma abordava, conteúdo e forma, fato que motivou essa investigação. Na pesquisa documental, foram levantadas e analisadas informações contidas nos RI, disponíveis nos sites das empresas participantes do programa piloto.

Como a publicação do Framework do RI foi em dezembro/2013, a amostra é composta pelos relatos de 2014 e 2015, pois alguns relatos de 2016 não estavam disponíveis. A intenção era pesquisar as doze empresas do PP no Brasil, do universo de 146 empresas em experimentação no mundo, mas alguns relatos não foram localizados, reduzindo a amostra para nove empresas, perfazendo um total de dezoito relatos. Neste estudo, as empresas foram identificadas como: Empresa 1, Empresa 2, Empresas 3, Empresas 4, Empresas 5, Empresa 6, Empresa 7, Empresa 8 e Empresa 9.

Devido a curta trajetória dos RI e o tamanho da amostra, optou-se pela flexibilidade da pesquisa qualitativa desenvolvida em quatro níveis, com auxílio do Software Nvivo 11 for Windows: (i) mapeamento da estrutura dos relatos para verificar se tem influência nos outros dados coletados; (ii) mapeamento da frequência de termos que fundamentam o RI; (iii) mapeamento da frequência de termos da informação financeira, oriundos das Demonstrações Contábeis, bem como a frequência de termos da informação não financeira; e (iv) análise da predisposição de integração das informações financeiras, por meio da linguagem visual, com base na concisão, completude, conectividade e comparabilidade. Tal sequência também orientou a exposição dos resultados da pesquisa.

\section{ANÁLISE DOS RESULTADOS}

\subsection{Estrutura dos Relatos}

Conforme a Tabela 1, são empresas de diferentes segmentos, com múltiplas denominações para o relato e variação na quantidade de páginas, características nem sempre determinantes para justificar os achados da pesquisa: 
Tabela 1: Dados sobre a estrutura dos Relatos Integrados no Brasil

\begin{tabular}{l|llccccc}
\multirow{2}{*}{ Empresa } & Segmento de atuação & \multicolumn{1}{c}{$\begin{array}{c}\text { Denominação do } \\
\text { relato }\end{array}$} & $\begin{array}{c}\text { Referência } \\
\text { ao termo RI }\end{array}$ & $\begin{array}{c}\text { Quantidade } \\
\text { de páginas }\end{array}$ & Formato \\
\cline { 2 - 8 } Empresa 1 & Energia & $\begin{array}{l}\text { Relatório de Sus- } \\
\text { tentabilidade }\end{array}$ & Sim & 40 & 39 & Sim & Sim \\
\hline Empresa 2 & Bancos & Relatório Anual & Sim & 52 & 60 & Sim & Sim \\
\hline Empresa 3 & Alimentos & $\begin{array}{l}\text { Relatório Anual e } \\
\text { de Sustentabilidade }\end{array}$ & Sim & 117 & 155 & Sim & Sim \\
\hline Empresa 4 & $\begin{array}{l}\text { Concessões rodoviá- } \\
\text { rias }\end{array}$ & $\begin{array}{l}\text { Relatório Anual e } \\
\text { de Sustentabilidade }\end{array}$ & $\begin{array}{c}\text { Não } \\
\text { (Em 2015) }\end{array}$ & 44 & 66 & Sim & Sim \\
\hline Empresa 5 & Energia & Relatório Anual & Sim & 136 & 121 & Sim & Sim \\
\hline Empresa 6 & Papel e celulose & Relatório & Sim & 152 & 100 & Sim & Sim \\
\hline Empresa 7 & Bancos & Relato Integrado & Sim & 37 & 59 & Sim & Sim \\
\hline Empresa 8 & Artigos de uso pessoal & Relatório Anual & Sim & 37 & 46 & Sim & Sim \\
\hline Empresa 9 & Industrial & Relatório Integrado & Sim & 168 & 164 & Sim & Sim \\
\hline TOTAL & & & & 783 & 810 & & \\
\hline
\end{tabular}

Fonte: Autoria própria com dados colhidos nos RI (2014 e 2015)

Apenas a Empresa 7 identifica como Relato Integrado e a Empresa 9, como Relatório Integrado (Tabela 1). As demais mantem a denominação anterior, tal como constatou Pereira (2016) na amostra com seis outras empresas da Europa, em 2015.

A maioria das empresas está em adaptação às orientações do Framework, ao acrescentar o RI no Relatório de Sustentabilidade/Relatório Anual. Essa unificação afeta a concisão ou a completude, pois há conflitos de finalidades, os relatórios específicos primam pela análise, ao passo que o RI prima pela síntese, caso haja necessidade, links podem levar aos detalhes nos relatórios específicos, prática inexistente na maioria dos relatos.

Em nome da concisão, menos é mais. Pois há diferença em ler 37 ou 168 páginas. E mais páginas não garantem mais qualidade na informação. Em relatos extensos, também, há ausência ou insuficiência de conteúdo necessários para evidenciar a criação de valor.

A Tabela 1, mostra a disponibilidade do RI em Portable Document Format [PDF] e On line, esta, mais dinâmica, ao possibilitar recursos de hipermídia e interações. A Empresa 8 até anuncia a versão on line como tendência, apesar de disponibilizar, também, a versão resumida em PDF, que permite impressão em formatos ajustados.

\subsection{Frequência de Termos Relacionados ao Relato Integrado}

Determinados termos fundamentam os propósitos do RI e contribuem na precisão e comparabilidade das informações. A Tabela 2 evidencia os termos presentes em todos os relatos, outros nem tanto. 
Tabela 2: Frequência de termos do Relato Integrado
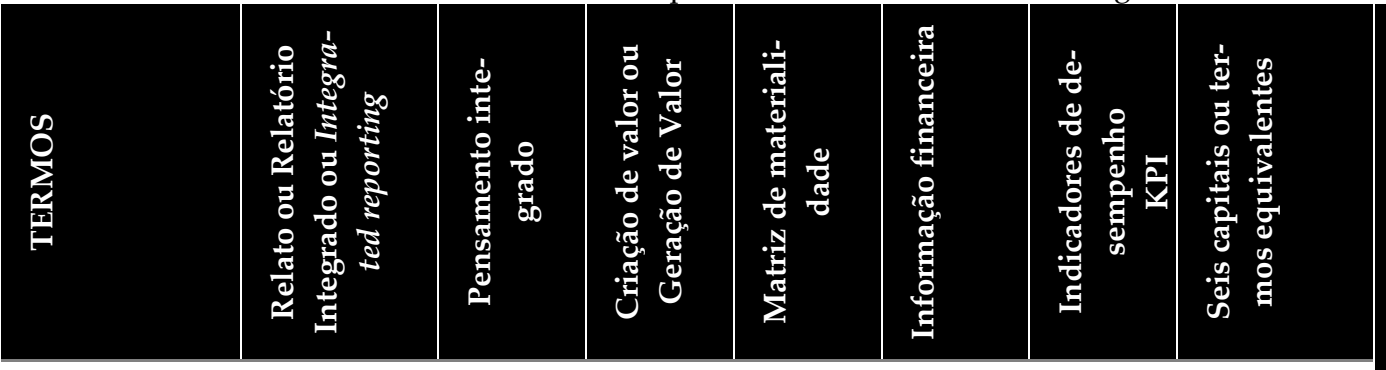

ANO

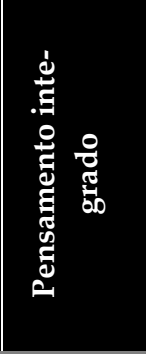

敬

EMPRESA

\begin{tabular}{|c|c|c|c|c|c|c|c|c|c|c|c|c|c|c|c|c|}
\hline Empresa 1 & 1 & 1 & 1 & 1 & 2 & 8 & 0 & 0 & 0 & 0 & 0 & 0 & 0 & 0 & 14 & $1,8 \%$ \\
\hline Empresa 2 & 2 & 2 & 0 & 0 & 0 & 1 & 0 & 0 & 0 & 0 & 0 & 0 & 3 & 6 & 15 & $1,9 \%$ \\
\hline Empresa 3 & 4 & 6 & 0 & 0 & 3 & 5 & 0 & 0 & 0 & 1 & 1 & 3 & 15 & 16 & 55 & $7,0 \%$ \\
\hline Empresa 4 & 5 & 0 & 0 & 0 & 13 & 23 & 0 & 0 & 1 & 0 & 0 & 0 & 40 & 79 & 161 & $20,6 \%$ \\
\hline Empresa 5 & 4 & 1 & 0 & 0 & 19 & 5 & 1 & 0 & 0 & 0 & 2 & 4 & 47 & 27 & 110 & $14,1 \%$ \\
\hline Empresa 6 & 6 & 1 & 0 & 0 & 13 & 8 & 2 & 2 & 3 & 1 & 1 & 0 & 4 & 2 & 44 & $5,6 \%$ \\
\hline Empresa 7 & 56 & 26 & 0 & 0 & 3 & 5 & 0 & 1 & 1 & 5 & 3 & 2 & 23 & 28 & 153 & $19,6 \%$ \\
\hline Empresa 8 & 2 & 2 & 0 & 0 & 4 & 2 & 1 & 0 & 1 & 0 & 0 & 0 & 0 & 1 & 13 & $1,7 \%$ \\
\hline Empresa 9 & 105 & 27 & 0 & 0 & 3 & 5 & 1 & 2 & 2 & 0 & 1 & 2 & 36 & 32 & 217 & $27,7 \%$ \\
\hline $\begin{array}{l}\text { Frequência } \\
\text { absoluta }\end{array}$ & 185 & 66 & 1 & 1 & 60 & 62 & 5 & 5 & 8 & 7 & 8 & 11 & 168 & 191 & 782 & $100 \%$ \\
\hline $\begin{array}{l}\text { Frequência } \\
\text { relativa/ano }\end{array}$ & $\begin{array}{l}\stackrel{0}{\circ} \\
\text { సे } \\
\text { సे }\end{array}$ & $\begin{array}{l}0^{\circ} \\
\text { in } \\
\infty\end{array}$ & $\stackrel{\circ}{\circ}$ & $\frac{\circ}{0}$ & $\stackrel{\circ}{\stackrel{2}{N}}$ & $\dot{0}_{\infty}^{\circ}$ & 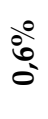 & i̊ & $\stackrel{\circ}{\circ}$ & ڤ̊ & $\stackrel{8}{\circ}$ & $\stackrel{\circ}{\stackrel{0}{+}}$ & 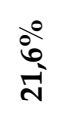 & $\begin{array}{l}\stackrel{0}{0} \\
\stackrel{i}{+}\end{array}$ & $\stackrel{\circ}{8}$ & \\
\hline $\begin{array}{l}\text { Frequência } \\
\text { relativa/termo }\end{array}$ & \multicolumn{2}{|c|}{$32,3 \%$} & \multicolumn{2}{|c|}{$0,3 \%$} & \multicolumn{2}{|c|}{$15,7 \%$} & \multicolumn{2}{|c|}{$1,3 \%$} & \multicolumn{2}{|c|}{$1,9 \%$} & \multicolumn{2}{|c|}{$2,4 \%$} & \multicolumn{2}{|c|}{$46,1 \%$} & $100 \%$ & \\
\hline
\end{tabular}

Fonte: Autoria própria com dados colhidos nos RI (2014 e 2015)

Pela Tabela 2, os termos Relato Integrado e seis capitais concentram quase $80 \%$ das frequências. Mas há termos elementares não citados em alguns relatos ou com baixa frequência:

- As Empresas 4, 5, 7 e 9 concentram a maioria dos termos pesquisados. Detalhe, as Empresa 4 e 7 tem os relatos mais sintéticos, indício de mais densidade na abordagem, diferente das Empresas 5 e 9 que estão entre os relatos com maior número de páginas (Tabela 2).

- A alta frequência do termo Relato Integrado nas divulgações das Empresas 7 e 9, em 2014, deve-se ao uso no rodapé das páginas. Por outro lado, no relato da Empresa 1, de 2014, aparece somente na última página, ao identificar o consultor. E das Empresas 5 e 6, de 2015, apenas ao detalhar a sigla IIRC - International Integrated Reporting Council.

- A Empresa 4, em 2015, nem cita o termo Relato Integrado, apesar de ser um dos mais fiéis às orientações do Framework: (i) faz referências às diretrizes do IIRC; (ii) estrutura do relato com base nos oito temas previstos no framework; (iii) destaca os seis capitais; e (iv) é um dos relatos dos mais concisos.

- Por sua vez, a frequência do termo pensamento integrado não representa nem $0,5 \%$ diante dos demais. Citado somente pela Empresa 1, básico na apuração da criação de valor pelo RI.

- Também foram baixas as frequências dos termos: indicadores de desempenho, informação financeira e matriz de materialidade. Essa, que contribui na concisão do RI e na satisfação dos usuários, foi citada por apenas cinco empresas, e somente por uma delas, nos dois anos.

- A Empresa 8 cita somente uma vez o termo informação financeira, ao identificar o responsável por esse tipo de informação, nos créditos finais. 
- O termo indicadores de desempenho, com potencial para integrar informações financeiras a não financeiras, também é ignorado por quatro das nove empresas, outra cita somente em 2014.

- O termo criação/geração de valor é um dos mais frequentes, mas tem empresa que cita apenas uma vez, em dois anos.

Pela alta frequência do termo seis capitais que se desdobra em seis outros, a Tabela 3 detalha a frequência de cada um.

Tabela 3: Frequência de termos por tipo de capital

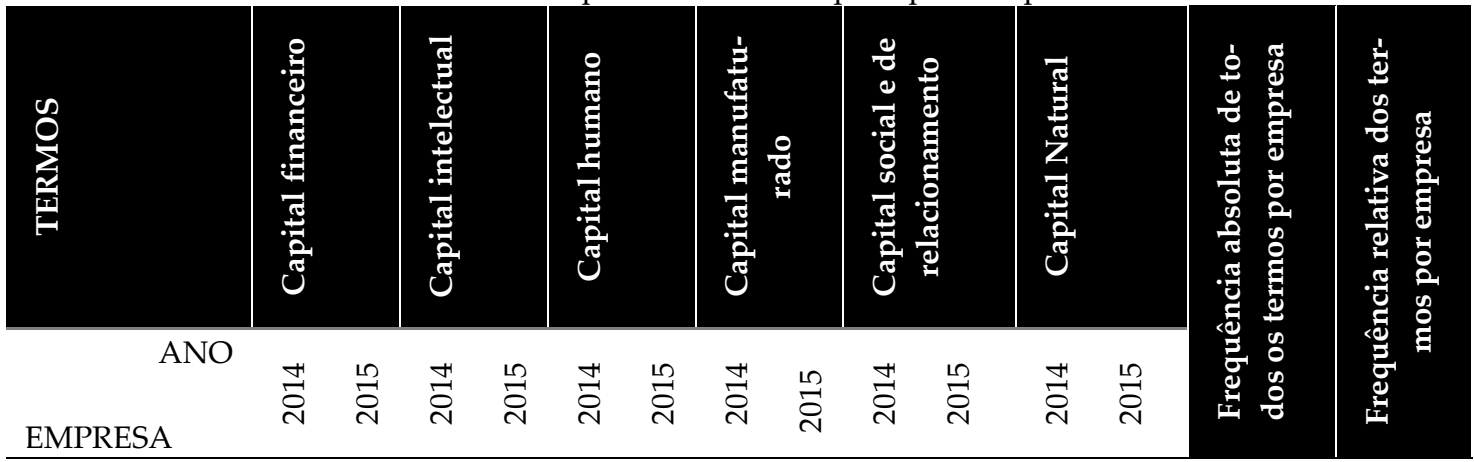

\begin{tabular}{|c|c|c|c|c|c|c|c|c|c|c|c|c|c|c|}
\hline Empresa 1 & 0 & 0 & 0 & 0 & 0 & 0 & 0 & 0 & 0 & 0 & 0 & 0 & 0 & $0 \%$ \\
\hline Empresa 2 & 1 & 0 & 1 & 1 & 0 & 1 & 0 & 1 & 1 & 2 & 0 & 1 & 9 & $3 \%$ \\
\hline Empresa 3 & 2 & 3 & 3 & 3 & 5 & 5 & 0 & 0 & 3 & 3 & 2 & 2 & 31 & $9 \%$ \\
\hline Empresa 4 & 7 & 17 & 8 & 10 & 9 & 13 & 4 & 11 & 7 & 17 & 4 & 8 & 115 & $33 \%$ \\
\hline Empresa 5 & 12 & 6 & 0 & 0 & 14 & 7 & 0 & 0 & 11 & 6 & 9 & 8 & 73 & $21 \%$ \\
\hline Empresa 6 & 0 & 0 & 0 & 0 & 2 & 0 & 0 & 0 & 1 & 1 & 1 & 1 & 6 & $2 \%$ \\
\hline Empresa 7 & 4 & 6 & 4 & 5 & 4 & 4 & 2 & 5 & 4 & 5 & 4 & 3 & 50 & $14 \%$ \\
\hline Empresa 8 & 0 & 0 & 0 & 0 & 0 & 0 & 0 & 0 & 0 & 0 & 0 & 1 & 1 & $0 \%$ \\
\hline Empresa 9 & 3 & 3 & 2 & 1 & 3 & 4 & 0 & 0 & 19 & 15 & 9 & 9 & 68 & $19 \%$ \\
\hline $\begin{array}{l}\text { Frequência } \\
\text { absoluta }\end{array}$ & 29 & 35 & 18 & 20 & 37 & 34 & 6 & 17 & 46 & 49 & 29 & 33 & 353 & $100 \%$ \\
\hline $\begin{array}{l}\text { Frequência re- } \\
\text { lativa/ano }\end{array}$ & $\stackrel{\infty}{\infty}^{\circ}$ & बूँ & $\stackrel{0}{\circ}$ & $\stackrel{\circ}{\stackrel{0}{\hat{k}}}$ & $\begin{array}{l}\text { o̊n } \\
\text { iñ }\end{array}$ & i̊ & $\stackrel{0}{\circ}$ & 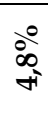 & 总 & $\begin{array}{l}\stackrel{\circ}{\sigma} \\
\text { ले }\end{array}$ & $\stackrel{\circ}{\infty}$ & iे & $\stackrel{\circ}{\circ}$ & \\
\hline $\begin{array}{l}\text { Frequência re- } \\
\text { lativa/termo }\end{array}$ & \multicolumn{2}{|c|}{$18,1 \%$} & \multicolumn{2}{|c|}{$10,8 \%$} & \multicolumn{2}{|c|}{$20,1 \%$} & \multicolumn{2}{|c|}{$6,5 \%$} & \multicolumn{2}{|c|}{$26,9 \%$} & \multicolumn{2}{|c|}{$17,6 \%$} & $100 \%$ & \\
\hline
\end{tabular}

Fonte: Autoria própria com dados colhidos nos RI (2014 e 2015)

Pela Tabela 3, capital social e de relacionamento, capital humano, capital financeiro e capital natural, nessa ordem, são os capitais mais frequentes nos dezoito relatos. E no conjunto, são mais frequentes nos relatos das Empresas 4, 5, 9 e 7.

- Dos seis capitais, a Empresa 8 fez referência apenas ao termo capital natural, e somente uma vez, apesar de abordar, assuntos relacionados aos capitais.

- A Empresa 6 também cita poucas vezes os capitais, mas trata de muitos assuntos correlatos. A Empresa 1 não cita os termos de nenhum dos capitais.

- A Empresa 2 cita uma vez o termo capital financeiro. A Empresa 6 cita várias vezes o termo "financeiro", associado a resultado, a mundo, a relatórios, a indicadores, a risco, mas não capital financeiro. As Empresas 1 e 8, também, não citam.

Portanto, ausência ou baixa frequência desses termos indica perda de oportunidade para massificar o vocabulário do RI e a própria integração. Constatação também evidente nos termos do capital financeiro.

\subsection{Frequência de Termos do Capital Financeiro}


Inicialmente, foram levantados termos que identificam as Demonstrações Contábeis previstas pelo CFC $(2008,2011,2016)$. A Tabela 4, evidencia baixa frequência desses termos.

Tabela 4: Frequência de termos que identificam as Demonstrações Contábeis no RI

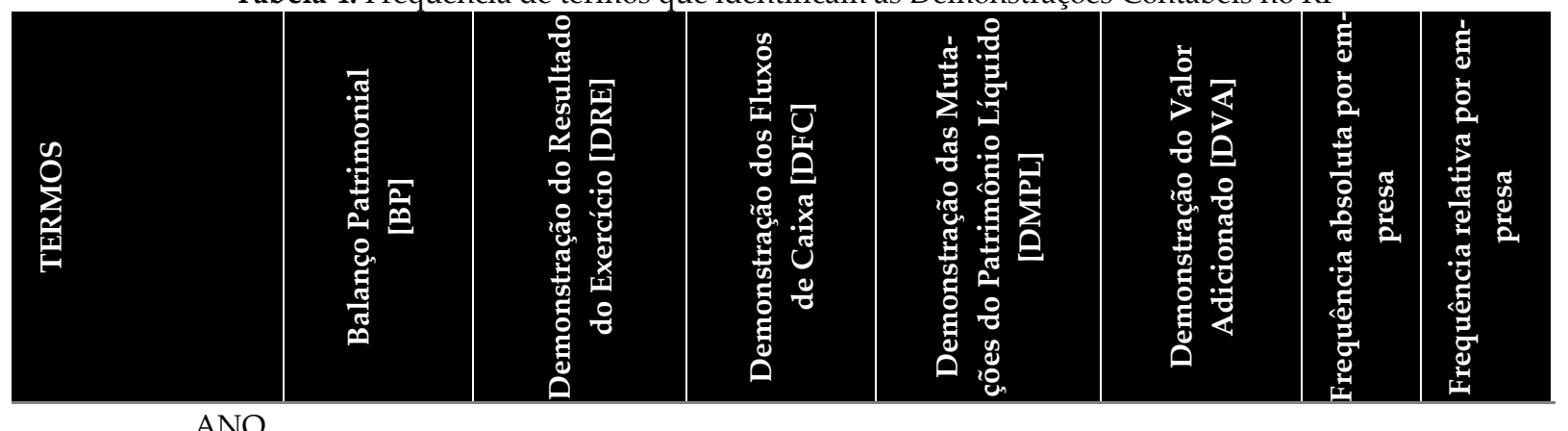

ANO

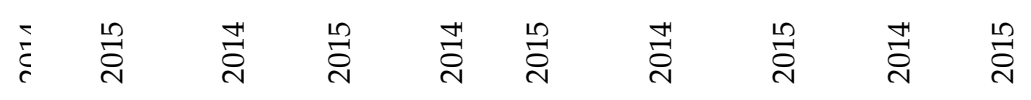

\begin{tabular}{|c|c|c|c|c|c|c|c|c|c|c|c|c|}
\hline EMPRESA & & & & & & & & & & & & \\
\hline Empresa 1 & 0 & 0 & 0 & 0 & 0 & 0 & 0 & 0 & 0 & 0 & 0 & $0 \%$ \\
\hline Empresa 2 & 0 & 0 & 0 & 0 & 0 & 0 & 0 & 0 & 2 & 2 & 4 & $12 \%$ \\
\hline Empresa 3 & 1 & 0 & 1 & 0 & 0 & 0 & 0 & 0 & 2 & 1 & 5 & $15 \%$ \\
\hline Empresa 4 & 0 & 0 & 0 & 0 & 0 & 0 & 0 & 0 & 0 & 0 & 0 & $0 \%$ \\
\hline Empresa 5 & 0 & 0 & 0 & 0 & 0 & 0 & 0 & 0 & 3 & 1 & 4 & $12 \%$ \\
\hline Empresa 6 & 0 & 0 & 0 & 0 & 0 & 0 & 0 & 0 & 0 & 0 & 0 & $0 \%$ \\
\hline Empresa 7 & 1 & 1 & 0 & 0 & 0 & 0 & 0 & 0 & 3 & 0 & 5 & $15 \%$ \\
\hline Empresa 8 & 0 & 0 & 0 & 0 & 0 & 0 & 0 & 0 & 0 & 0 & 0 & $0 \%$ \\
\hline Empresa 9 & 2 & 1 & 0 & 0 & 2 & 2 & 1 & 1 & 4 & 2 & 15 & $45 \%$ \\
\hline $\begin{array}{l}\text { Frequência abso- } \\
\text { luta }\end{array}$ & 4 & 2 & 1 & 0 & 2 & 2 & 1 & 1 & 14 & 6 & 33 & $100 \%$ \\
\hline $\begin{array}{l}\text { Frequência rela- } \\
\text { tiva/ano }\end{array}$ & $\begin{array}{l}\dot{\prime} \\
\stackrel{c}{r} \\
\dot{r}\end{array}$ & $\stackrel{\circ}{\frac{0}{6}}$ & $\stackrel{\circ}{\grave{0}}$ & 官 & $\stackrel{\circ}{\stackrel{\circ}{\sigma}}$ & $\stackrel{\circ}{\stackrel{\circ}{6}}$ & 官 & 官 & 京 & 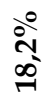 & 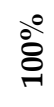 & \\
\hline $\begin{array}{l}\text { Frequência rela- } \\
\text { tiva/termo }\end{array}$ & & & & & & & & & & & & \\
\hline
\end{tabular}

Fonte: Autoria própria com dados colhidos nos RI (2014 e 2015)

Pela Tabela 4, foram apenas 33 citações em 18 relatos, no total de 1.593 páginas:

- A DVA é a demonstração contábil mais citada (60,6\%), talvez por influência do Relatório de Sustentabilidade, onde é importante fonte de informação. Ainda assim, nove relatos de cinco empresas não citaram.

- DRE, DFC e DMPL são citadas por apenas uma empresa nos dois anos.

- A Empresa 9 concentra $45 \%$ da frequência de termos que identificam as Demonstrações Contábeis, única empresa que anexa tais demonstrações. Mas seus relatos figuram entre os mais extensos (completude sem concisão).

Quatro empresas não citam nenhuma das demonstrações pelo nome oficial. Mas, podem citalas por outros termos, como demonstra a Tabela 5. 
Tabela 5: Frequência de outros termos que fazem referências às Demonstrações Contábeis no RI

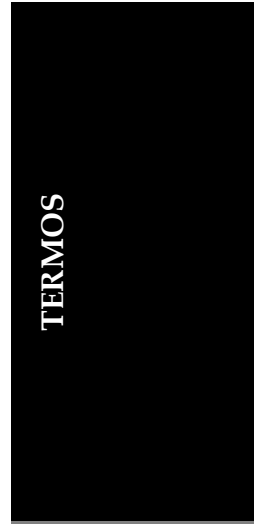

$\mathrm{ANO}$
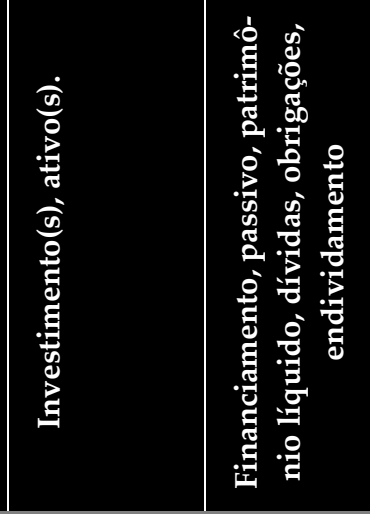

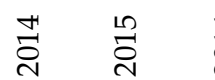
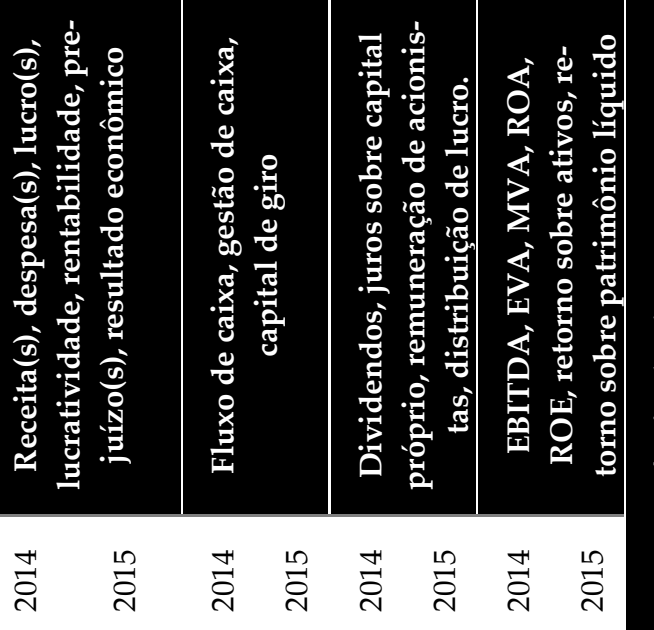

EMPRESA

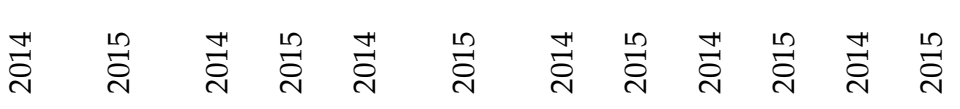

\begin{tabular}{rrrrrrrrrrrrrrrrr}
\hline Empresa 1 & 16 & 15 & 1 & 0 & 1 & 2 & 24 & 18 & 0 & 0 & 0 & 0 & 4 & 1 & 82 & $3 \%$ \\
\hline Empresa 2 & 155 & 119 & 79 & 81 & 1 & 0 & 40 & 41 & 8 & 2 & 3 & 5 & 3 & 2 & 539 & $18 \%$
\end{tabular}

\begin{tabular}{lllllllllllllllll}
\hline Empresa 3 & 68 & 72 & 15 & 23 & 0 & 0 & 105 & 103 & 12 & 6 & 7 & 6 & 20 & 19 & 456 & $15 \%$ \\
\hline
\end{tabular}

\begin{tabular}{lllllllllllllllll}
\hline Empresa 4 & 59 & 68 & 4 & 5 & 0 & 0 & 41 & 38 & 0 & 0 & 5 & 4 & 6 & 4 & 234 & $8 \%$ \\
\hline
\end{tabular}

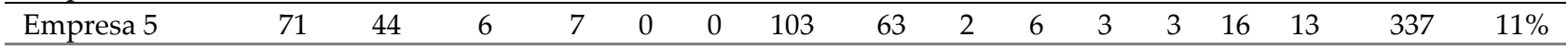

\begin{tabular}{lllllllllllllllll}
\hline Empresa 6 & 34 & 44 & 18 & 12 & 1 & 0 & 80 & 53 & 0 & 0 & 2 & 10 & 6 & 3 & 263 & $9 \%$ \\
\hline
\end{tabular}

\begin{tabular}{lllllllllllllllll}
\hline Empresa 7 & 70 & 131 & 26 & 21 & 0 & 1 & 76 & 88 & 0 & 1 & 10 & 13 & 0 & 2 & 439 & $15 \%$ \\
\hline
\end{tabular}

\begin{tabular}{rrrrrrrrrrrrrrrrr}
\hline Empresa 8 & 27 & 29 & 2 & 0 & 0 & 0 & 33 & 31 & 0 & 2 & 3 & 2 & 8 & 6 & 143 & $5 \%$ \\
\hline Empresa 9 & 113 & 94 & 23 & 28 & 0 & 0 & 107 & 99 & 5 & 6 & 11 & 13 & 16 & 18 & 533 & $18 \%$ \\
\hline
\end{tabular}

\begin{tabular}{lllllllllllllllll}
\hline $\begin{array}{l}\text { Frequência } \\
\text { absoluta }\end{array}$ & $\mathbf{6 1 3}$ & $\mathbf{6 1 6}$ & $\mathbf{1 7 4}$ & $\mathbf{1 7 7}$ & $\mathbf{3}$ & $\mathbf{3}$ & $\mathbf{6 0 9}$ & $\mathbf{5 3 4}$ & $\mathbf{2 7}$ & $\mathbf{2 3}$ & $\mathbf{4 4}$ & $\mathbf{5 6}$ & $\mathbf{7 9}$ & $\mathbf{6 8}$ & 3026 & $100 \%$ \\
\hline
\end{tabular}

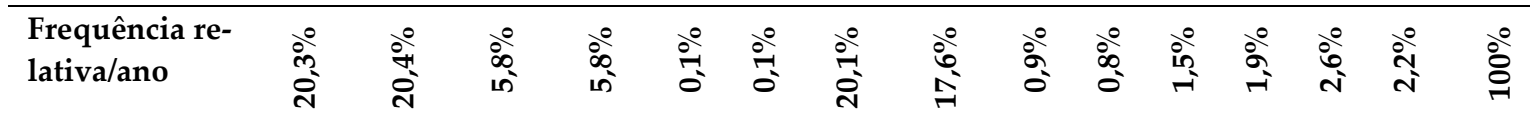

\begin{tabular}{lllllll}
\hline $\begin{array}{l}\text { Frequência re- } \\
\text { lativa/termo }\end{array}$ & $40,6 \%$ & $11,6 \%$ & $0,2 \%$ & $37,8 \%$ & $1,7 \%$ & $3,3 \%$
\end{tabular}$\quad 4,9 \%$

Fonte: Autoria própria com dados colhidos nos RI $(2014,2015)$

No geral, as Demonstrações Contábeis são mais evidenciadas por meio de termos que retratam aspectos essenciais ou sinônimos, como demonstra a Tabela 5:

- 52,2\% da frequência de termos está nas colunas de investimento e financiamento, sinônimos de ativo e de passivo/patrimônio líquido, respectivamente. Foram 1.580 citações, algumas podem nem retratar o BP. Mas levantamento específico aos termos ativo, passivo e patrimônio líquido identificou 102 citações, bem acima das 6 citações do termo Balanço Patrimonial, na Tabela 4.

- A Empresa 4 cita ativo e patrimônio líquido, mas não cita passivo, apesar das referências a dívidas e obrigações. A Empresa 8 cita ativo da biodiversidade e princípio ativo de um produto, mas não o utiliza no sentido contábil. A Empresa 1, não menciona os termos passivo e patrimônio líquido, mas cita financiamento.

- Termos da coluna de receita, despesa, lucro, prejuízo estão em todos os relatos, $37,8 \%$ do total de termos da Tabela 5, são 1.143 citações referentes a DRE, bem diferente da única citação na Tabela 4.

- Continua baixa a frequência aos termos da DFC (caixa). Três empresas não citam nenhum dos termos, outras duas citam apenas em 2015. Informação crucial para tomada de decisão. 
- Por sua vez, a DMPL, citada por apenas uma empresa na Tabela 4, alcançou 100 citações, em 16 relatos, conforme Tabela 5, por meio dos termos dividendos, juros sobre capital próprio, remuneração de acionistas e distribuição de lucro.

- Indicadores de desempenho foi termo raro na Tabela 2, mas teve 147 citações aos termos EBITDA, EVA, MVA, ROE, ROA. Dessas, 131 são referências ao EBITDA. Contradizendo o estudo de Lopes et al. (2017).

- O termo ativo intangível é ausente em treze dos dezoito relatos, apesar de citarem capital intelectual (38 vezes), capital humano (71) e capital de relacionamento (95), conforme Tabela 5. E segundo a Ocean Tomo (2015), o intangível já representa mais de $80 \%$ do valor atual das quinhentas empresas com ações mais valorizadas na NYSE e NASDAQ.

- A Tabela 5, também, indica que 93\% desses termos estão presentes nos relatos de sete das nove empresas pesquisadas, com variações entre $8 \%$ e $18 \%$ por empresa; isso representa distribuição equilibrada entre os relatos da amostra.

Para confirmar a frequência de termos, foi feita a nuvem das cem palavras mais frequentes, com seus respectivos sinônimos e variações de número, excluídas palavras com menos de cinco letras, bem como artigos, preposições, verbos, nome de empresas e de países.

As mais frequentes, referentes às informações financeiras: valor, investimentos, resultados, ações, desempenho, financeiro, recursos, crédito, indicadores, vendas, índices, custos, econômico e capital; perfazendo um total de quatorze. Por sua vez, oitenta e seis palavras retratam informações não financeiras: empresa, gestão, energia, relatório, negócios, projetos, processos, desenvolvimento, riscos, produtos, clientes, ambiental, companhia, sustentabilidade. A distribuição é aproximada, pois algumas dessas palavras podem retratar informações financeiras e não financeiras.

Para aumentar o rigor, foram levantados termos financeiros oriundos das Demonstrações Contábeis, presentes no sumário de cada relato, pois o sumário sintetiza os tópicos mais relevantes dos relatos.

$\mathrm{Na}$ contagem dos quinze termos financeiros mais frequentes, acima de cinco letras, juntamente com seus sinônimos, foram identificados: investimento(s) (25 citações); valor(es) (22); EBITDA (18); lucro (18); receita (17); resultado(s) (17); patrimônio (15); adicionado (12); ativo(s) (12); caixa (12); capital (11); dividendos (10); despesa(s) (7); passivo (6); e custo(s) (5).

No mapeamento dos quinze termos não financeiros dos sumários, com seus respectivos sinônimos, foram identificados: governança (16 citações); estratégia (15); negócio(s) (14); social (11); gestão (10); modelo (9); administração (7); contexto (7); desempenho (7); relacionamento (7); sustentabilidade (7); humano (6); natural (6). Os seguintes termos empataram nas duas últimas classificações, com cinco citações cada: atuação; desenvolvimento; futuro; informações e inovação.

Mapeados os conteúdos, resta identificar a forma de evidenciação das informações financeiras e sua predisposição para integração com outras informações.

\subsection{Predisposição de integração das informações financeiras via linguagem visual}

Como as demonstrações contábeis são desmembradas em informações essenciais, para atender a princípios como: concisão, conectividade, completude e comparabilidade, as informações financeiras são reordenadas e sintetizadas com outros recursos de linguagem, além do texto verbal, que possibilitam ilustração, animação e interação, com uso de hipertexto, infográficos e hipermídia. Mas o escopo deste artigo, é a linguagem visual dos relatos impressos, pois o referencial teórico não adentra em linguagem audiovisual.

E ao invés de mapear e comparar formatos por empresas, optou-se por explorar iniciativas que inspirem aprimoramentos de futuros relatos, devido a curta trajetória do Framework do RI, que não define formatos de divulgação, além de serem experiências de um programa piloto. 
Assim, a Figura 3 é exemplo de concisão, completude e comparabilidade, ao exibir, em apenas três colunas e três cores, os três elementos essenciais do BP, na sequência de três anos. Caso haja necessidade de detalhamento, o link remete ao relatório específico:

Figura 3: Composição do patrimônio em R\$ milhões

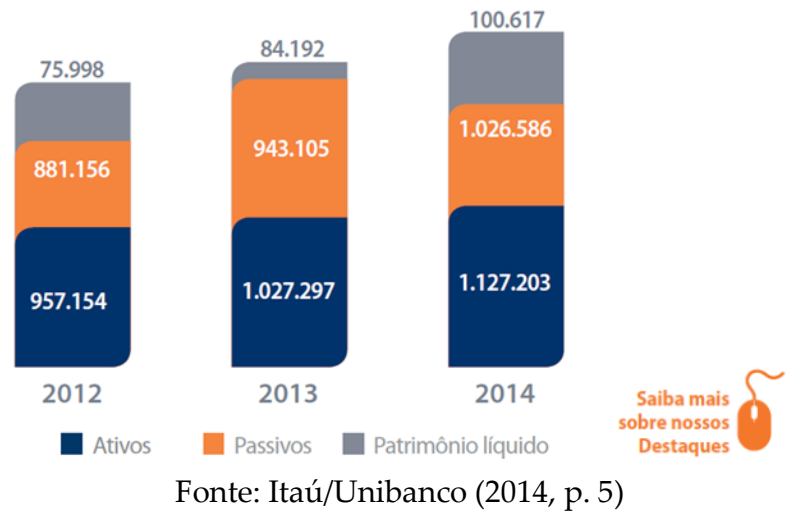

Pela dimensão das formas e diferenças de cores (linguagem visual) da Figura 3 identifica-se a variação no passivo como causa da diminuição do patrimônio líquido no ano de 2013. E com auxílio dos números, percebe-se que a empresa reverteu a situação pelo aumento do patrimônio líquido em 2014.

Por outro lado, a Figura 4 apresenta o BP em linguagem visual não tão sintética, mas com forte apelo visual, em cinco anos de performance, potencializando a comparabilidade e a análise de tendência, em sintonia com a informação retrospectiva e prospectiva, proposta por Carvalho e Kassai (2014). Nessa figura, também é evidente a integração entre linguagem visual e linguagem verbal, na busca da completude. 
Figura 4: Balanço Patrimonial
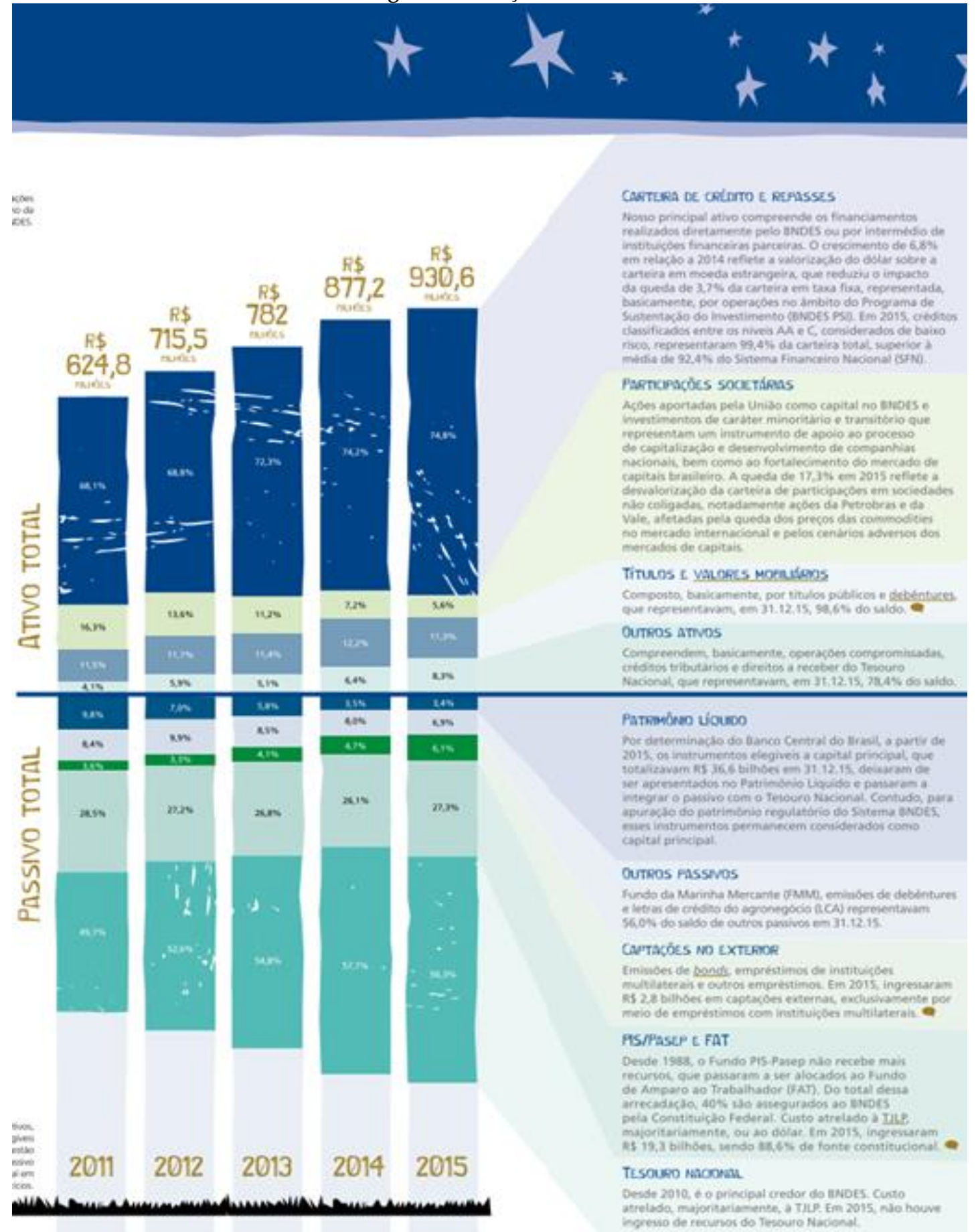

Fonte: Relato Integrado BNDES (2015, p. 20)

A Figura 4 poderia ser melhorada, se o Patrimônio Líquido estivesse fora do Passivo Total, por resultar da diferença entre ativo e passivo, sinônimo de capital próprio, enquanto o passivo representa capital de terceiros, obrigação. Tal consideração está amparada pelo princípio da clareza, para facilitar o entendimento.

A Figura 5 retrata indicadores de desempenho de forma concisa, comparável e conectada, com informações da DRE e do BP. 
Figura 5: Indicadores de desempenho financeiro

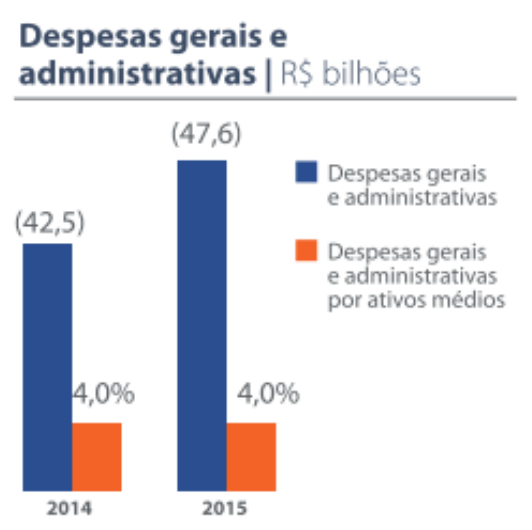

Retorno sobre o patrimônio e sobre os ativos médios

Fonte: Itaú/Unibanco (2015, p. 38)

Pelo primeiro indicador (Figura 5), as despesas gerais e administrativas crescem, mas continuam em $4 \%$ do ativo médio, que cresceu na mesma proporção. Novamente, o uso de cores e formas é determinante, com auxílio dos números.

Na segunda parte da Figura 5, as variações do índice de retorno sobre patrimônio líquido e do índice de retorno sobre ativos médios são integradas ao comparar com o crescimento da Taxa Selic Meta, que teve crescimento mais vigoroso.

De outro modo, a Figura 6 exemplifica concisão e comparabilidade ao focar aspectos essenciais da DVA (distribuição). A diferença em relação às orientações do IASB, se dá por ocultar a apuração do valor adicionado e incluir a variação \%, facilitando a comparação.

Figura 6: Valor Adicionado

\begin{tabular}{|c|c|c|c|}
\hline DVA & 2015 & 2014 & Var. \% \\
\hline Recursos humanos & 4.776 & 4.607 & 3,67 \\
\hline Impostos & 3.239 & 4.064 & $-20,30$ \\
\hline Juros/aluguéis & 5.346 & 2.857 & 87,12 \\
\hline Juros sobre capital próprio & 899 & 738 & 21,82 \\
\hline Retenção & 1.839 & 1.401 & 31,26 \\
\hline Participação de acionistas não controladores & 20 & (0) & - \\
\hline Dividendos & 91 & 86 & 5,81 \\
\hline Total & 16.210 & 13.753 & 17,87 \\
\hline
\end{tabular}

Fonte: BRF (2015, p. 76)

A Figura 7 intensifica a concisão da DVA, ao explicitar o tamanho das diferentes fatias de valor adicionado destinadas a cada tipo de agente. Entretanto, essa figuração sacrificou o comparativo com outro ano. 
Figura 7: Distribuição do Valor Adicionado

VALOR ADICIONADO

DISTRIBUIDO| 2014

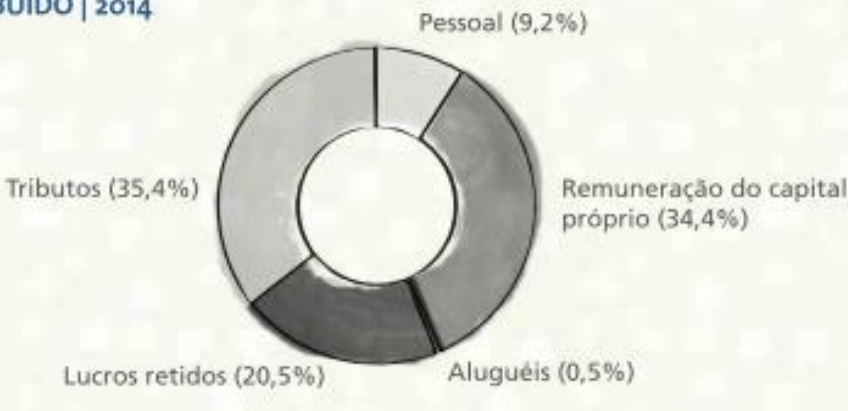

Fonte: BNDES (2014, p. 19)

A Figura 8 explora concisão, conectividade e comparabilidade ao compilar informações financeiras e não financeiras no decorrer de três anos. Figuração que potencializa o pensamento integrado com informações de diferentes relatórios.

Figura 8: Indicadores Financeiros

\begin{tabular}{lcc|c}
\hline PRINCIPAIS INDICADORES FINANCEIROS & $\mathbf{2 0 1 2}$ & $\mathbf{2 0 1 3}$ & $\mathbf{2 0 1 4}$ \\
\hline Receita líquida de vendas (R\$ milhões) & 6.174 & 6.917 & 7.084 \\
\hline Lucro líquido (R\$̦ milhões) & -698 & -698 & 163 \\
\hline Ativo (R\$̦ milhões) & 28.133 & 26.750 & 25.594 \\
\hline Patrimônio líquido (R\$ milhões) & 15.193 & 14.491 & 14.616 \\
\hline Ebitda (R\$ milhões) & 2.253 & 2.796 & 2.791 \\
\hline Dívida líquida /Ebitda UDM (US\$) & 3,3 & 2,6 & 2,4 \\
\hline Produção de celulose (toneladas mil) & 5.299 & 5.257 & 5.274 \\
\hline Vendas de celulose (toneladas mil) & $5.357,0$ & 5.198 & 5.305 \\
\hline Valor de mercado (R\$̦ bilhões) & 12,5 & 15,3 & 18,0 \\
\hline Custo caixa de produção (R\$̦/t) & 473 & 505 & 519 \\
\hline Valor da ação - FIBR3 (R\$̦) em 31/12 & 22,6 & 27,6 & 32,5 \\
\hline
\end{tabular}

Fonte: Empresa 6 (2014, p. 130)

Da Figura 8, deduz-se várias informações integradas: (i) com menos investimentos (ativos), em 2014, a empresa gera mais receita e reverte o prejuízo dos anos anteriores; (ii) os prejuízos são influenciados por despesas com juros, imposto de renda, contribuição social e despesas que não implicam em desembolso, como depreciação e amortização, tanto que o lucro apurado antes de tais despesas (EBITDA) é positivo nos três anos evidenciados; (iii) o crescimento do valor de mercado do produto favoreceu o aumento da receita, pois a quantidade vendida em 2014 é inferior a 2012; (iv) a melhoria nos indicares de desempenho surtiram efeito na cotação das ações no mercado, no decorrer dos anos.

Tais integrações podem ser ampliadas para além do capital financeiro e do capital manufaturado explorados nessa tabela, com divulgação de políticas voltadas ao capital humano e capital intelectual para melhoria da qualidade do produto e/ou retenção de talentos, bem como a divulgação de indicadores ambientais (capital natural) e a relação com a cadeia produtiva e comunidade do entorno (capital de relacionamento).

Nessa linha, a Figura 9 apresenta indicadores econômicos, ambientais, sociais e operacionais, junto ao plano de negócios (omitido por falta de espaço). Isso favorece o pensamento integrado na tomada de decisão, ao conjugar informações passadas, presentes e futuras, bem como, financeiras e não financeiras. Mas a integração vai além da simples aproximação das informações. 
Figura 9: Indicadores financeiros e não financeiros

\section{Econômico}

\begin{tabular}{|c|c|c|c|}
\hline $\begin{array}{l}\text { Indicadores econômicos } \\
\text { (R\$ milhöes) }\end{array}$ & 2013 & 2014 & 2015 \\
\hline Receita líquida consolidada & $7.010,3$ & $7.408,4$ & $7.899,0$ \\
\hline Ebitda consolidado & $1.609,0$ & $1.554,5$ & $1.495,9$ \\
\hline Lucro líquido consolidado & 842,6 & 732,8 & 513,5 \\
\hline Geração de caixa livre & 295,1 & 208,6 & 818,1 \\
\hline $\begin{array}{l}\text { Volume médio diário negociado } \\
\text { de açōes }{ }^{\prime}\end{array}$ & 61,1 & 47,9 & 30,2 \\
\hline Percentual de Ols na receita (\%) & 16,1 & 19,2 & 27,0 \\
\hline $\begin{array}{l}\text { Distribuiçáo de riqueza } \\
\text { (R\$ milhöes) }\end{array}$ & 2013 & 2014 & 2015 \\
\hline Acionistas $^{2}$ & 854 & 702 & 352 \\
\hline Consultoras & 4. 107 & 4.122 & 4.166 \\
\hline Colaboradores & 917 & 1.075 & 1.245 \\
\hline Fornecedores & 5.425 & 5.925 & 6.374 \\
\hline Governo & 1.804 & 1.724 & 2.149 \\
\hline
\end{tabular}

Legenda:

Ok: Operaçòes Internacionais; CNs: Consultoras Natura; CNOs:

Consultoras Natura Orientadoras.

Notas:

'Fonte: Bloomberg

${ }^{2} \mathrm{O}$ s valores equivalem a dividendos e juros sobre o capital próprio efetivamente pagos aos acionistas, ou seja, consideram o regime de caixa.

$8^{+} 8$ Social

\begin{tabular}{lccc}
\hline Qualldade das relaçōes (\%) & 2013 & 2014 & 2015 \\
\hline $\begin{array}{l}\text { Pesquisa de clima - Favorabilidade } \\
\text { colaboradores (Brasil e Ols) }\end{array}$ & 78 & 75 & 78 \\
$\begin{array}{l}\text { Lealdade fornecedores (Brasil e Ols) } \\
\text { ( }\end{array}$ & 30 & 24 & 18 \\
\hline Lealdade CNs Brasil & 23 & 28 & 30 \\
\hline Lealdade CNOs Brasil & 38 & 30 & 29,5 \\
\hline Lealdade consumidor Brasil & 52 & 64 & 58 \\
\hline Lealdade CNs Ols & 38 & 39 & 37 \\
\hline Lealdade CNOs Ols & 47 & 45 & 52
\end{tabular}

SPesquisa de clima - Hay Group.

PPesquisa de lealdade - Instituto Ipsos.
A Ambiental

\begin{tabular}{lccc}
\hline & 2013 & 2014 & 2015 \\
\hline $\begin{array}{l}\text { Emissäo relativa de gases GEE } \\
\left(\mathrm{kg} \mathrm{CO}_{2} \mathrm{e} / \mathrm{kg} \text { produto faturado) }\right.\end{array}$ & 2,93 & 3,00 & 3,17 \\
$\begin{array}{l}\text { Emissōes GEE na cadeia de valor } \\
\text { (milhares t) }\end{array}$ & 328.452 & 332.326 & 321.267 \\
$\begin{array}{l}\text { Consumo de água (l/unidade } \\
\text { produzida) }\end{array}$ & 0,40 & 0,45 & 0,49 \\
$\begin{array}{l}\text { \% material reciclado } \\
\text { pós-consumo }\end{array}$ & 1,4 & 1,2 & 2,9 \\
\hline $\begin{array}{l}\text { \% embalagens ecoeficientes } \\
\text { (5 }\end{array}$ & 22 & 29 & 26 \\
\hline
\end{tabular}

${ }^{3} \mathrm{CO}_{2}$ (ou $\mathrm{CO}$, equivalente): medida utilizada para expressar as emissóes dos pases de efeito estufa, baseada no potencial de aquecimento global de cada um.

"Inclui escopos 1, 2 e 3 do GHG Protocol.

'Embalagens com redução de, no mínimo, 50\% em relação à

embalagem regular/similar ou que apresentam $50 \%$ de sua composiçào com materiais pós-consumo ejou material renovável năo celulósico,

desde que não apresentem aumento de massa.

\section{Demais indicadores}

\begin{tabular}{lccc}
\hline & 2013 & 2014 & 2015 \\
\hline $\begin{array}{l}\text { Avaliação global de pesquisa de } \\
\text { imagem de marca no Brasil (\%) }\end{array}$ & 78 & 74 & 73 \\
$\begin{array}{l}\text { Arrecadaçăo Crer para Ver } \\
\text { (R\$ milhōes) }\end{array}$ & 21,9 & 25,5 & 30 \\
$\begin{array}{l}\text { Negócios acumulados na regiä。 } \\
\text { amazônica (R\$ milhōes) }\end{array}$ & 385 & 582 & 752 \\
$\begin{array}{l}\text { Familias beneficiadas nas } \\
\text { comunidades fornecedoras }\end{array}$ & 3.117 & 3.121 & 2.251 \\
\hline
\end{tabular}

¿Pesquisa Brand Essence - Instituto Ipsos.

"Reduçào influenciada pelo encerramento do relacionamento com duas comuridades e da classificaçăo de uma terceira como "sem atividade" (sem compra de insumo).

Fonte: Natura (2014, p. 11)

A Figura 9, também, potencializa a evidenciação da criação de valor pela empresa no futuro, via análise de tendência e linguagem visual que facilita a leitura por uso de cores, formas e espaços, facilitando julgamentos mais fundamentados pelos usuários.

Nesses sete exemplos, há diferentes predisposições de integração de informações para evidenciar a criação de valor de forma clara, concisa, conectada e comparável. Em todos é visível a presença dos fundamentos de Santaella (2002), Silva (2006) e Lencastre e Chaves (2007), quanto ao uso de cores, formas e espaços em novas recursos de linguagem (hipertexto e infográficos) em prol da comunicação com envolvimento e intenção.

\section{CONCLUSÃO}

Diante do objetivo deste estudo em descrever conteúdos e formas de divulgação das informações financeiras para evidenciar a criação de valor nos RI, foi constatado, as empresas estão em 
adaptação às orientações do Framework do RI para evidenciar a criação de valor por meio do pensamento integrado, pois a maioria dos RI foi adaptada aos Relatórios Anuais e de Sustentabilidade. Apenas, uma empresa o intitula como Relato Integrado, e outra, como Relatório Integrado, as demais mantém a denominação anterior, apesar de anunciarem seguir as orientações do IIRC, previstas no Framework. Consequência, no Brasil, há relatos de 37 a 168 páginas, o que sinaliza necessidade de adequação ao princípio da concisão, sem perder de vista a completude.

Quanto a frequência de termos, são pouco utilizados os termos pensamento integrado, matriz de materialidade e indicadores de desempenho. Por outro lado, há várias referências aos termos criação de valor e aos seis capitais.

Quanto ao capital financeiro, surpreende o uso esporádico do termo ativo intangível, dada a representatividade no valor dos patrimônios atuais, como atestou a Ocean Tomo (2015). Entretanto, os relatos fazem várias menções a questões afins. E o tratamento aos ativos intangíveis é um dos diferenciais do RI, por reconhecer os capitais intelectual, humano e de relacionamento. A baixa evidenciação do intangível também foi atestada por Mazzioni, Di Domenico e Bedin (2014), em pesquisa com 50 empresas listadas na BM\&FBOVESPA.

A pesquisa constatou, as Demonstrações Contábeis, raramente, são evidenciadas na íntegra. Também são raras as referências aos termos Balanço Patrimonial e Demonstração do Resultado do Exercício, dois emblemáticos relatórios financeiros. O RI os expõe em informações essenciais, por meio de termos como: ativo, passivo, patrimônio líquido, receitas e despesas, ou seus sinônimos, investimento, financiamento e resultado/lucro. A DVA é a Demonstração Contábil mais evidenciada, mais que a DFC, talvez por influência do Relatório de Sustentabilidade.

Dentre aos indicadores de desempenho financeiro, o EBITDA, a rentabilidade, a distribuição do valor adicionado e a distribuição de dividendos/remuneração de acionistas figuram entre os mais frequentes, no levantamento feito nos sumários dos relatos.

Outro ponto positivo, identificado neste estudo, foi o uso da linguagem visual para expressar as informações financeiras, em sintonia com os princípios da concisão, da completude, da conexão e da comparabilidade. Algumas dessas imagens conectam informações financeiras e não financeiras, potencializando o pensamento integrado.

Apesar deste estudo ter limitações devido a curta trajetória do RI e o número de empresas pesquisadas, ao meio acadêmico contribui para constatar a abordagem interdisciplinar do Relato Integrado ao conectar propósitos da Administração, da Contabilidade e da Comunicação. À gestão das empresas, contribuiu para desdobrar o framework do RI e mostrar a interface entre forma e conteúdo na evidenciação da criação de valor. Merece consideração o processo de aprendizagem das empresas do PP, que leva a ajustes de um ano para o outro, na busca de conteúdos e formatos mais adequados.

Nesse sentido, este estudo abre possibilidades de aprofundamento dessa abordagem no campo da Contabilidade, da Administração e da Comunicação. Seja no tratamento aos ativos intangíveis, na sistematização e proposição de indicadores integrados para medir desempenhos, na identificação do nível de satisfação com o RI a partir do ponto de vista dos usuários ou do relato de experiência das equipes de elaboradores, ou mesmo, da análise da linguagem envolvendo parâmetros audiovisuais. Também, pode-se ampliar a amostra, incluindo empresas estrangeiras, relatos de anos subsequentes e outros métodos de pesquisa.

Enfim, os resultados positivos precisam ser multiplicados e os negativo, relativizados, afinal, todo processo de experimentação está sujeito ao aprimoramento, e o Relato Integrado envolve quebra de paradigmas tanto na integração de conteúdo, quanto no formato da linguagem. Desta feita, o aprimoramento é salutar, e a disposição para a mudança, elementar. 


\section{REFERÊNCIAS}

Carvalho, N., \& Kassai, J. R. (2014, agosto). Relato integrado: a nova revolução contábil. Revista FIPECAFI, 1, 21-34. Recuperado de: https://issuu.com/revistafipecafi/docs/revista_vol_1_corrigido.

Comissão de Valores Mobiliários. (2005). Deliberação CVM no 488, de 03 de outubro de 2005. Recuperado de: http://www.cvm.gov.br/export/sites/cvm/legislacao/deliberacoes/anexos/0400/deli488.pdf

Conselho Federal de Contabilidade. (2008). Resolução CFC no 1.138/08. Brasília. Recuperado de: http://www1.cfc.org.br/sisweb/sre/detalhes_sre.aspx?Codigo=2008/001138

Conselho Federal de Contabilidade. (2011). Resolução CFC no 1.374/11. Brasília. Recuperado de: http://www.normaslegais.com.br/legislacao/resolucao-cfc-1374-2011.htm

Conselho Federal de Contabilidade. (2016). NBC TG 26 R4. Brasília. Recuperado de: http://www2.cfc.org.br/sisweb/sre/detalhes_sre.aspx?Codigo=2016/NBCTG26R4\&arquivo=NBCTG26R4.doc

Da Cunha, J. V., Morais, A. I., \& Rodrigues, M. A. (2016). Integrated reporting - IR: o novo paradigma em corporate reporting. Revisores e Auditores, 34-41. Recuperado de: http://www.oroc.pt/fotos/editor2/Revista/72/Contabilidade.pdf

Da Silva, S. L. (2011). Stakeholders, recursos e criação de valor. Navus-Revista de Gestão e Tecnologia, 1(1), 105-111. Doi: https://doi.org/10.22279/navus.2011.v1n1.p105-111.18.

Eccles, R. G., \& Krzus, M. P. (2011). Relatório único: divulgação integrada para uma estratégia sustentável. São Paulo: Saint Paul Editora.

Eccles, R. G., \& Spiesshofer, B. (2015, September, 25) Integrated reporting for a re-imagined capitalism. Harvard Business School General Management Unit Working Pape. 16-032.

Doi.org/10.2139/ssrn.2665737.

Ernst \& Young. (2014). Relato Integrado: pensamento, estratégia e valor compartilhado. Recuperado de: http://www.ey.com.br/Publication/vwLUAssets/Relato_Integrado_2014/\$FILE/RelatoIntegrado_WEB.pdf.

Ferreira-Quilice, T., \& Caldana, A. C. F. (2015). Aspectos negativos no modelo de reporte proposto pela GRI: a opinião das organizações que reportam. Revista de Administração (São Paulo), 50(4), 405-415. Doi: http://dx.doi.org/10.5700/rausp1209.

Garrison, R. H., Noreen, E. W., \& Brewer, P. C. (2013). Contabilidade gerencial. (14a‥ ed.). Porto Alegre: AMGH Editora. Recuperado de: https://books.google.com.br/books.

Gonzaga, R. P., Da Cruz, A. P. C., Pereira, C. A., \& Da Luz, A. T. M. (2015). Associação entre missão institucional declarada por empresas brasileiras e seus indicadores de desempenho. Contabilidade Vista \& Revista, 26(1). Recuperado de: http://www.redalyc.org/html/1970/197038251002/

GRI. (2013) G4 Diretrizes para o relatório de sustentabilidade. Princípios para o relatório e conteúdo padrão. Global Reporting Reporting Initiative. Amsterdam. Recuperado de:

https://www.globalreporting.org/resourcelibrary/Brazilian-Portuguese-G4-Part-Two.pdf.

Havlová, K. (2015). What integrated reporting changed: the case study of early adopters. Procedia Economics and Finance, 34, 231-237. Doi: 10.1016/S2212-5671(15)01624-X 
International Federation of Accountants (2015). Creating value with integrated thinking: the role of professional accountants. Recuperado em: http://html5.epaperflip.com/?docid=169c6165-6ce1411e-aacc-a561002373a4\#page $=1$

Institute of Chartered Accountant of England and Wales. (2009). Developments in new reporting models. Financial Reporting Faculty of ICAEW. Recuperado de http://www.aaajournals.org/doi/pdf/10.2308/accr.00000004

Instituto Brasileiro de Governança Corporativa (2015). Código das Melhores Práticas de Governança Corporativa (5⿳亠口冋. . ed.) Recuperado de: http://www.ibgc.org.br/userfiles/2014/files/codigoMP_5edicao_web.pdf

International Integrated Reporting Council. (2011). Discussion paper: towards integrated reporting - Communicating value in the 21st century. Recuperado de: http://theiirc.org/wp-content/uploads/2011/09/IR-Discussion-Paper-2011_spreads.pdf

International Integrated Reporting Council. (2013). The international framework. Recuperado de: http://www.theiirc.org/wp-content/uploads/2013/12/13-12-08-THE-INTERNATIONAL-IRFRAMEWORK-2-1.pdf.

Jensen, J. C.; \& Berg, N. (2012). Determinants of traditional sustainability reporting versus integrated reporting, an institutionalist approach. Business Strategy and the Environment, 21(5), 299316. doi: 10.1002/bse.740.

Klovienè, L., \& Speziale, M. T. (2014). Sustainability reporting as a challenge for performance measurement: Literature review. Economics and Business, 26, 44-53. Recuperado de: http://dx.doi.org/10.7250/eb.2014.019.

Lencastre, J. A., \& Chaves, J. H. (2007). A imagem como linguagem. In Libro de actas do IX Congreso Internacional Galego-Portugués de Psicopedagoxía (pp. 1162-1173). Universidade da Coruña. Recuperado de: https://repositorium.sdum.uminho.pt/handle/1822/26093.

Lopes, A. C., De Luca, M. M. M., Góis, A. D., \& de Vasconcelos, A. C. (2017). Disclosure Socioambiental, Reputação Corporativa e Criação de Valor nas Empresas Listadas na BM\&FBovespa. Revista Ambiente Contábil, 9(1), 364-382. Recuperado de: https://search.proquest.com/openview/5fe9b991a2f16378e1523381c38e9b66/1?pq-origsite=gscholar\&cbl=2036235

Mazzioni, S., Di Domenico, D., \& Bedin, H. N. (2014). Evidenciação de informações dos ativos intangíveis em empresas brasileiras de capital aberto. Revista GEINTEC-Gestão, Inovação e Tecnologias, 4(5), 1501-1520. Doi: 10.7198/geintec.v4i5.446

Ocean Tomo. (2015). Components of S\&P 500 Market value, 2015. Recuperado de: http://www.oceantomo.com/2015/03/04/2015-intangible-asset-market-value-study/.

Pereira, D. A. C. (2016). Relato integrado: utopia ou realidade. Dissertação de Mestrado, Instituto Politécnico de Setúbal. Escola Superior de Ciências Empresariais, Setúbal. Recuperado de: https://comum.rcaap.pt/handle/10400.26/14349.

Perrotta, C. (2004). Um texto pra chamar de seu: preliminares sobre produção de texto acadêmico. São Paulo: Martins Fontes.

Roth, H. P. (2014). Is integrated reporting in the future? The CPA Journal, 84(3), 62-67. Recuperado de: http://search.proquest.com/openview/bf2e09b0c0aa60f813abb567c6de6d6b/1?pqorigsite $=$ gscholar

Santaella, L. (2002). Semiótica aplicada. São Paulo: Thomson. 
Silva, J. M. da. (2006). Interfaces: Michel Maffesoli, teórico da comunicação. Revista Famecos: mídia, cultura e tecnologia, 1(25). Recuperado de: http://revistas.univerciencia.org/index.php/famecos/article/viewArticle/401. 